\title{
Soluble CD40 Ligand as a Predictor of Coronary Artery Disease and Long-Term Clinical Outcomes in Stable Patients Undergoing Coronary Angiography
}

\author{
Matthew T. Rondina ${ }^{a}$ Jason M. Lappéb John F. Carlquist ${ }^{a, b}$ \\ Joseph B. Muhlestein ${ }^{a, b}$ Matthew J. Kolek ${ }^{b}$ Benjamin D. Horne ${ }^{b}$ \\ Robert R. Pearson ${ }^{b}$ Jeffrey L. Anderson ${ }^{a, b}$ \\ ${ }^{\mathrm{a}}$ Department of Internal Medicine, University of Utah School of Medicine and ${ }^{\mathrm{b}}$ Cardiovascular Department, \\ LDS Hospital, Salt Lake City, Utah, USA
}

\section{Key Words}

Soluble CD40 ligand - Coronary artery disease $\cdot$

Inflammation $\cdot \mathrm{C}$-reactive protein $\cdot$ Cardiovascular risk

\begin{abstract}
Background: In patients with acute coronary syndrome (ACS), elevated levels of soluble CD40 ligand (sCD40L) are associated with increased risk of cardiovascular events. We evaluated SCD40L levels and future cardiovascular events in patients not experiencing ACS. Methods: Serum sCD40L levels were measured in 909 patients undergoing angiography. A three-way matching scheme (age, gender and catheterization time period) identified 303 patients with coronary artery disease (CAD) who experienced a cardiac event within 1 year (CAD/event), 303 patients with CAD free of events (CAD/no event) and 303 patients without CAD and free of events (no CAD). Results: Average age was $64 \pm 11$ years; $74 \%$ were males. Median ( $\pm \mathrm{SE}$ ) sCD40L levels were higher for no CAD patients $(335 \pm 60 \mathrm{pg} / \mathrm{ml}$ ) compared to CAD (248 $\pm 65 \mathrm{pg} / \mathrm{ml}, \mathrm{p}=0.01)$ and to CAD/event $(233 \pm 63 \mathrm{pg} / \mathrm{ml}$, $p<0.001)$. There was no significant difference in median SCD40L levels between CAD/no event and CAD/event patients. Higher SCD40L quartiles were associated with a sig-
\end{abstract}

nificant decrease in the risk of $C A D /$ event versus no $C A D$ (quartile 4 versus quartile 1 : odds ratio $=0.59, p=0.03$ ). There was a nonsignificant trend towards a decreased risk of CAD as compared to no CAD, and for CAD/event versus CAD. Conclusions: In non-ACS patients, higher SCD40L levels were associated with a decreased risk of CAD. This novel interaction of $S C D 40 L$ raises interesting questions for CAD pathogenesis.

Copyright $\odot 2007$ S. Karger AG, Basel

\section{Introduction}

Markers of myocardial cell necrosis, most notably troponin I and troponin $\mathrm{T}$, have been invaluable in the rapid diagnosis of acute coronary syndrome (ACS). However, these markers do not measure coronary plaque stability, leukocyte activation or platelet aggregation, processes that contribute to inflammation and thrombosis. Since inflammation and thrombosis are critical factors in ACS, the development of markers that identify the upregulation of these processes could result in the earlier identification of patients with high-risk atherosclerotic lesions.

\section{KARGER}

Fax +41613061234 E-Mail karger@karger.ch www.karger.com (c) 2007 S. Karger AG, Basel

0008-6312/08/1093-0196\$24.50/0

Accessible online at:

www.karger.com/crd
Matthew T. Rondina, MD

Department of Internal Medicine, University of Utah School of Medicine

30 North 1900 East, Room 4C106

Salt Lake City, Utah 84132 (USA)

Tel. +1 801581 7899, Fax +1 801585 0418, E-Mail matthew.rondina@hsc.utah.edu 
Platelet-monocyte (heterotypic) aggregates are important in the pathogenesis of atherosclerotic lesions [1] and appear to be an early marker of ACS [2]. One marker of platelet aggregation that plays an important role in thrombosis and plaque destabilization is CD40 ligand (CD40L) $[3,4]$. CD40L and its receptor CD40 are found on a variety of cells, including endothelial cells, smooth muscle cells and platelets [5]. Binding of CD40L and CD40 stimulates endothelial cells and smooth muscle cells to express molecules critical for leukocyte adhesion, which leads to atherogenesis, including vascular cell adhesion molecule-1, E-selectin and intercellular adhesion molecule-1 [5].

The soluble form of CD40, soluble CD40L (sCD40L), is released after platelet stimulation [6,7] and induces tissue factor expression on monocytes [8] and endothelial cells [9], accelerating the inflammatory process and promoting coagulation. Patients with ACS [10] and unstable angina [11] have elevated levels of sCD40L when compared to controls. In addition, elevated levels of sCD40L independently predict risk of future death and recurrent myocardial infarction (MI) in patients with ACS [12]. Among healthy women [13], sCD40L levels were significantly higher among participants who developed acute MI (AMI), stroke or suffered a cardiovascular death than among age- and smoking-matched controls. However, to date, no study has prospectively correlated SCD40L levels and coronary artery disease (CAD) risk in stable, nonACS patients. The current study investigated the correlation between baseline sCD40L levels in non-AMI patients admitted for coronary angiography and the risk of CAD, death and AMI during long-term follow-up.

\section{Methods}

\section{Study Hypothesis}

We tested the hypothesis that baseline sCD40L levels in stable, non-MI patients would not differ among 3 age- and gendermatched groups. The first group consisted of patients with CAD who experienced a future cardiovascular event (CVE), the second group included patients with CAD who did not have a future CVE and the third group comprised patients without CAD or a future CVE. All patients were followed for 1 year.

\section{Patients}

Patients undergoing coronary angiography were enrolled in the cardiac catheterization registry of the Intermountain Heart Collaborative Study. Study participants were adults 18 years of age or older but otherwise of unrestricted age and sex who were evaluated by angiography for suspected CAD or other conditions requiring angiographic evaluation. Patients included individuals admitted for AMI, unstable angina or stable exertional angina, and were referred for angiography from throughout Utah as well as from southwest Wyoming, southern Idaho and eastern $\mathrm{Ne}$ vada. Participants provided written informed consent for blood drawn at angiography to be used in confidential blood bank studies. This study was approved by the hospital's institutional review board.

A three-way matching scheme [by age ( \pm 5 years), gender and time period of catheterization ( \pm 1 year)] was used to identify 303 patients with CAD ( $\geq 70 \%$ stenosis in $\geq 1$ major vessel) who experienced a CVE such as death or AMI within 1 year of follow-up, 303 patients with CAD but with no CVE and 303 free from CAD and CVE, in a nested case-control design. Patients presenting with AMI [unstable angina (progressive symptoms or symptoms at rest) or $\mathrm{AMI}$ (creatine kinase $\mathrm{MB}>6 \mathrm{mg} / \mathrm{dl}$ and creatine kinase MB index $>3 \%)$ ] were excluded.

Assessment of CAD was made by review of angiograms by a cardiologist (blinded to the results of blood testing for inflammatory and serological markers) and results were entered into the computer database in a format modified after the Coronary Artery Surgery Study (CASS) protocol [14]. At the time of cardiac catheterization, a blood specimen was obtained from each patient and stored for analyses.

Demographics, including age, gender, diabetes mellitus, hyperlipidemia, hypertension, smoking and family history of coronary heart disease, were collected using computerized data forms. Prehospital medication use was not known and thus medication use could not be compared between patients. Diabetes was defined as a history of fasting blood sugar $\geq 126 \mathrm{mg} / \mathrm{dl}$ or use of antidiabetic medication. Hypertension was defined as systolic blood pressure $\geq 140 \mathrm{~mm} \mathrm{Hg}$, diastolic blood pressure $\geq 90 \mathrm{~mm}$ $\mathrm{Hg}$ or treatment with antihypertensive medication. Hyperlipidemia was defined as a total cholesterol $\geq 200 \mathrm{mg} / \mathrm{dl}$, low-density lipoprotein cholesterol $\geq 130 \mathrm{mg} / \mathrm{dl}$ or use of a cholesterol-lowering agent. Family history was positive if a first-order relative had a cardiovascular death, MI or coronary revascularization before 65 years of age. Tobacco use included active smokers and those with a smoking history $>10$ pack-years.

Determination of $s C D 40$ L Levels

Serum sCD40L levels were measured by enzyme-linked immunosorbent assay (R\&D Systems) and separated into 4 quartiles: quartile 1 (Q1) was an sCD40L level $<108 \mathrm{pg} / \mathrm{ml}$, quartile 2 (Q2) was $108-273 \mathrm{pg} / \mathrm{ml}$, quartile 3 (Q3) was $274-648 \mathrm{pg} / \mathrm{ml}$ and quartile 4 (Q4) was $\geq 649 \mathrm{pg} / \mathrm{ml}$.

\section{Determination of C-Reactive Protein}

Testing for C-reactive protein (CRP) was performed with the use of a fluorescence polarization immunoassay (TDxFLEx Analyzer, Abbott Diagnostics). After determination of all baseline CRP levels, the cohort was divided into tertiles (CRP 1st tertile $<1.2 \mathrm{mg} / \mathrm{dl}$, 2nd tertile $1.2-1.7 \mathrm{mg} / \mathrm{dl}$ and $3 \mathrm{rd}$ tertile $>1.7 \mathrm{mg} / \mathrm{dl}$ ), based on individual patient CRP values. This medium sensitivity assay has been shown to have differing (higher) values than highsensitivity methods but to be at least as predictive of outcomes [15].

Statistical Considerations

Comparison of sCD40L levels to other covariates and study endpoints was performed using the t-test or analysis of variance (ANOVA) after normalization of the numerical distribution by 
Table 1. Baseline demographics stratified by study endpoint

\begin{tabular}{lllll}
\hline Characteristic & Overall & $\begin{array}{l}\text { No } \\
\text { CAD }\end{array}$ & CAD & $\begin{array}{l}\text { CAD/ } \\
\text { event }\end{array}$ \\
\hline $\begin{array}{l}\text { Matching criteria } \\
\quad \text { Age, years }\end{array}$ & $64 \pm 11$ & $64 \pm 11$ & $64 \pm 11$ & $65 \pm 10$ \\
$\quad \begin{array}{l}\text { Male, \% } \\
\text { Cardiac risk factors }\end{array}$ & 74 & 74 & 74 & 74 \\
$\quad$ Hypertension, \% & 54 & 44 & $62^{\mathrm{a}}$ & $59^{\mathrm{a}}$ \\
$\quad$ Hyperlipidemia, \% & 51 & 35 & $58^{\mathrm{a}}$ & $59^{\mathrm{a}}$ \\
$\quad \begin{array}{l}\text { Diabetes, \% } \\
\text { Smoking, \% }\end{array}$ & 18 & 10 & $21^{\mathrm{a}}$ & $25^{\mathrm{a}}$ \\
$\quad$ Family history, \% & 34 & 21 & 24 & 24 \\
$\quad$ High CRP, \% & 51 & 43 & 32 & 37 \\
\hline
\end{tabular}

${ }^{\mathrm{a}} \mathrm{p}<0.017$ versus no $\mathrm{CAD} ;{ }^{\mathrm{b}} \mathrm{p}<0.017$ versus CAD. natural logarithmic transformation. The ANOVA test of linear contrast of the means was used to evaluate trends across the 3 endpoints simultaneously. The $\chi^{2}$ test or ANOVA was used to compare quartiles of sCD40L and endpoints to study covariates.

Logistic regression was used to evaluate the association of sCD40L quartiles to study endpoints with adjustment for demographics and risk factors. Adjusted odds ratios (OR) and 95\% confidence intervals (CI) were computed from these predictive models. Further statistical correction was performed, due to the multiple tests that were evaluated to compare the endpoints of no CAD versus $C A D$, no $C A D$ versus $C A D /$ event, and $C A D$ versus CAD/event. The Bonferroni correction, a conservative method for multiple comparison adjustment, was used to set the critical $\mathrm{p}$ value for significance at $\mathrm{p}=0.017$.

\section{Results}

The 3 groups were balanced (table 1), with patient age averaging $64 \pm 11$ years. Of the patients, $74 \%$ were male, $54 \%$ had hypertension, $51 \%$ had hyperlipidemia and $18 \%$ had diabetes. As expected, patients with CAD and CAD/ event had a higher incidence of hypertension, hyperlipidemia and diabetes than patients without CAD $(\mathrm{p}<0.017)$. Patients with CAD who experienced a CVE were more likely to have a high CRP than patients without CAD and patients with CAD but without a CVE $(\mathrm{p}<0.017)$. There were no significant differences in smoking or family history of CAD in the 3 groups. There were no significant differences in any of the baseline characteristics when stratified by sCD40L quartiles (table 2).

Median ( \pm SE) sCD40L levels were significantly higher in patients without CAD $(335 \pm 60 \mathrm{pg} / \mathrm{ml})$ compared to patients with CAD who did not have a CVE $(248 \pm 65$

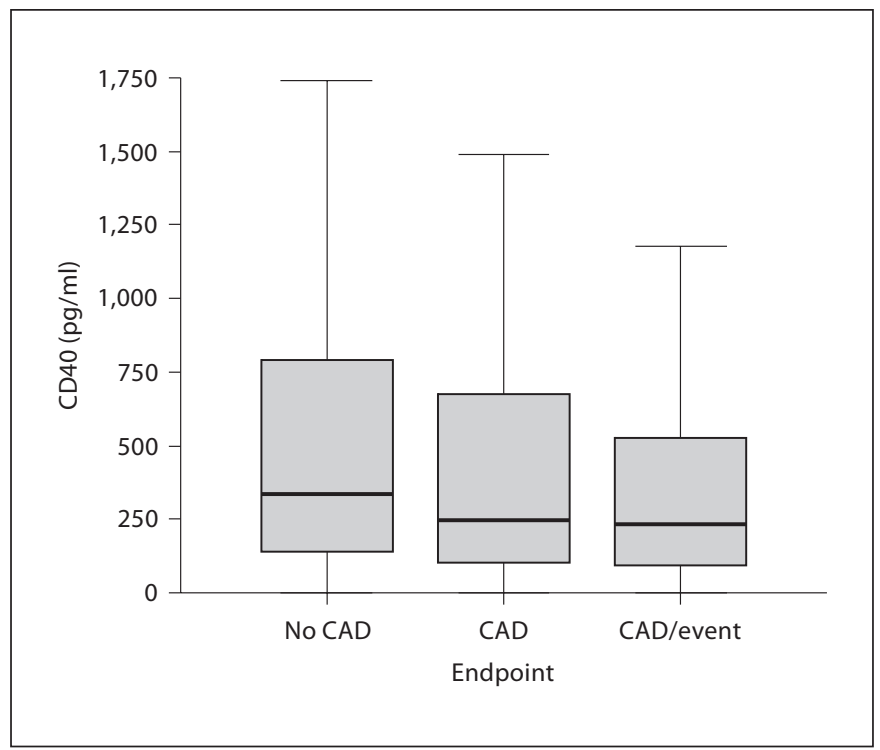

Fig. 1. Box plot of sCD40L levels by disease endpoint. A significant inverse relationship was discovered (linear trend: $p<0.001$ ), although this disappeared after multivariable adjustment.

$\mathrm{pg} / \mathrm{ml}, \mathrm{p}=0.01)$ and to patients with CAD who did have a CVE $(233 \pm 63 \mathrm{pg} / \mathrm{ml}, \mathrm{p}<0.001)$. Median sCD40L levels were not significantly different between patients with CAD who did not have a CVE and patients with CAD who did have a CVE ( $p=0.24$; fig. 1$)$.

Higher sCD40L levels were associated with a nonsignificant trend towards a decreased risk of CAD versus no CAD (Q4 vs. Q1: adjusted OR $=0.71,95 \% \mathrm{CI}=0.44-1.13$, $\mathrm{p}=0.15)$ and $\mathrm{CAD} /$ event versus no $\mathrm{CAD}(\mathrm{Q} 4$ vs. Q1: $\mathrm{OR}=0.59, \mathrm{CI}=0.37-0.96, \mathrm{p}=0.03)$, but not for CAD/ event versus CAD (Q4 vs. Q1: $\mathrm{OR}=0.89, \mathrm{CI}=0.56-1.41$, $\mathrm{p}=0.61$; table 3 ). Analyses showed no differences between men and women.

\section{Discussion}

In this patient population, elevated baseline sCD40L did not predict CAD and was not associated with a higher risk of death or MI. Interestingly, although not statistically significant, patients with CAD had lower sCD40L levels than patients without CAD. This is the first study, to our knowledge, to investigate the association between baseline sCD40L levels in a heterogenous population of stable non-ACS patients and long-term outcomes.

A few other studies have investigated SCD40L levels in patients without ACS. Schonbeck et al. [13] published a 
Table 2. Baseline characteristics stratified by sCD40L quartile

\begin{tabular}{|c|c|c|c|c|c|c|}
\hline \multirow[t]{2}{*}{ Characteristic } & \multirow[t]{2}{*}{ Overall } & \multicolumn{4}{|c|}{ sCD40L quartile } & \multirow[t]{2}{*}{$\mathrm{p}$ value } \\
\hline & & Q1 & Q2 & Q3 & Q4 & \\
\hline Age, years & $64 \pm 11$ & $64 \pm 11$ & $64 \pm 11$ & $66 \pm 10$ & $64 \pm 11$ & 0.30 \\
\hline Male, $\%$ & 74 & 74 & 75 & 73 & 73 & 0.94 \\
\hline Hypertension, \% & 54 & 52 & 54 & 59 & 52 & 0.37 \\
\hline Hyperlipidemia, \% & 51 & 55 & 50 & 50 & 49 & 0.52 \\
\hline Diabetes, $\%$ & 18 & 20 & 18 & 16 & 18 & 0.82 \\
\hline Smoking, \% & 23 & 25 & 24 & 21 & 23 & 0.69 \\
\hline Family history, \% & 34 & 35 & 34 & 36 & 33 & 0.89 \\
\hline High CRP, \% & 51 & 47 & 51 & 51 & 52 & 0.70 \\
\hline
\end{tabular}

Statistical comparisons are from a 3 d.f. ANOVA or Pearson's $\chi^{2}$ test.
Table 3. Multivariable logistic regression results for SCD40L quartiles

\begin{tabular}{lcll}
\hline & CAD versus no CAD & CAD/event versus no CAD & CAD/event versus CAD \\
\hline Q1 & 1.0 (referent) & 1.0 (referent) & 1.0 (referent) \\
Q2 & $0.79(0.48-1.3)$ & $0.95(0.59-1.53)$ & $1.26(0.80-1.80)$ \\
Q3 & $1.1(0.66-1.7)$ & $0.80(0.49-1.30)$ & $0.81(0.52-1.28)$ \\
Q4 & $0.71(0.44-1.1)$ & $0.59(0.37-0.96)^{*}$ & $0.89(0.56-1.41)$ \\
\hline
\end{tabular}

Data are presented as OR with $95 \%$ CI in parentheses. Covariables in the multivariable adjustments included hypertension, hyperlipidemia, diabetes, smoking, family history and high CRP (patients were matched on age and gender). ${ }^{*} \mathrm{p}=0.03$ (Bonferroni correction, critical $\mathrm{p}=0.017)$. prospective, nested case-control study among healthy, middle-aged females (130 cases, 130 controls) participating in the Women's Health Study (WHS). Cases and controls were age- and smoking-matched and followed for 4 years. Mean sCD40L concentrations at baseline were higher among the 130 cases who developed MI, cerebrovascular accident or cerebrovascular death compared to those controls who remained free of these events (2.86 $\mathrm{ng} / \mathrm{ml}$ vs. $2.09 \mathrm{ng} / \mathrm{ml}, \mathrm{p}=0.02)$. However, as the authors point out, most cases and controls had similar sCD40L levels at study entry; the difference in mean sCD40L levels was due almost entirely to an excess of very high values among cases (11 cases vs. 1 control had sCD40L levels greater than the 99 th percentile cut point of $5.54 \mathrm{ng} / \mathrm{ml}$ ). As a result, the study is limited by the small number of cases with markedly elevated SCD40L levels and the homogenous population (i.e. women only).

Tanne et al. [16] also evaluated sCD40L among more than 3,000 patients with chronic coronary disease. They found no increase in the odds of ischemic stroke or recurrent coronary events based on levels of sCD40L, with a relative odds of 0.97 . In stratifying results by ischemic stroke and by recurrent coronary events, though, they did find potential trends toward decreased risk of recurrent coronary events (relative odds $=0.35$ ) for elevated sCD40L, similar to the current study.

Previous studies in patients with ACS found that increased levels of sCD40L were associated with an increased risk of death and MI. For example, Heeschen et al. [10] reported that in patients with ACS or acute chest pain, higher sCD40L levels were associated with a significantly increased risk of death or nonfatal MI at 6 months. Similarly, Varo et al. [12] published a nested case-control study of 195 cases with ACS and 195 controls. Patients who experienced one of the prespecified endpoints (death, MI or congestive heart failure) had significantly higher median sCD40L levels than controls $(p<0.002)$. When sCD40L levels were divided into quartiles, patients with sCD40L levels in the third and fourth quartiles were more likely to experience an MI or the composite of death and MI.

Our finding that sCD40L levels in stable non-ACS patients were not predictive of long-term adverse CVE is novel. Although the precise mechanism is unknown, one 
potential theory is that platelet activation and $\mathrm{SCD} 40 \mathrm{~L}$ release is upregulated during ACS but not in stable CAD. Platelet activation at the site of plaque rupture occurs during ACS $[4,17,18]$ and is characterized, in part, by the formation of platelet-leukocyte aggregates. Higher numbers of circulating platelet-leukocyte aggregates have been found in patients with AMI or ACS $[2,19,20]$ and unstable angina [21] compared to patients who had noncardiac chest pain or stable angina. In addition, circulating levels of platelet-leukocyte aggregates increase after percutaneous coronary angioplasty $[19,22]$, a procedure which disrupts the endothelium, resulting in platelet activation. Another possibility for our findings is confounding by antiplatelet therapy in those with known CAD, which might be responsible for reducing sCD40L release from platelets. It is likely that patients with CAD were on aspirin therapy at the time of enrollment, while those without CAD were less likely to be on aspirin.

Since platelet activation leads to increased sCD40L release $[6,7]$, it is no surprise that levels of sCD40L are higher in patients with unstable angina, the pathophysiology of which is plaque rupture, compared to patients with stable angina or noncardiac chest pain. Aukrust et al. [11] studied 29 patients with stable angina, 26 patients with unstable angina and 19 controls. Patients with unstable angina had significantly higher sCD40L levels when compared to either patients with stable angina or controls. Cardiopulmonary bypass [22] and percutaneous coronary angioplasty [11], procedures which disrupt the endothelium leading to platelet activation, induce a rise in sCD40L levels. Taken together, these studies suggest that unlike CRP, $\mathrm{SCD} 40 \mathrm{~L}$ is not a marker for chronic inflammation and coronary atherosclerosis but instead is an indicator of platelet activation that may play a more significant role in the ACS patient than the stable patient without ACS.

\section{Limitations}

This study may be limited by the potential biases inherent in observational studies, including that patients were potentially at higher CAD risk than the general population. These findings should be replicated, including comparisons to controls from the general population. However, some potential confounders were dealt with by design (i.e. age and sex) and others by multivariable analyses (i.e. hypertension, hyperlipidemia, diabetes, smoking, family history and high CRP). A strength of the study is that the actual coronary status of each patient was known from the gold standard test (i.e. angiography), thus eliminating the clinical uncertainty inherent in many population-based studies where the study endpoint is a surrogate $\mathrm{CAD}$ measure (e.g. symptoms) or only acute events are measured.

\section{Conclusion}

In contrast to previously reported information in patients with acute coronary syndrome, in these stable patients elevated levels of sCD40L did not predict CAD and were not associated with a higher risk of clinical events (death, MI). In fact, a trend towards lower sCD40L levels in stable CAD compared to non-CAD patients was observed. This novel finding that $\mathrm{SCD} 40 \mathrm{~L}$ levels did not predict increased risk of death or MI in stable nonACS patients suggests that unlike CRP, sCD40L is not associated with chronic inflammation; rather, it increases during acute ischemia in response to platelet aggregation and activation. Additional studies are needed to further clarify the role of sCD40L in coronary heart disease.

\section{References}

1 Huo Y, Schober A, Forlow SB, Smith DF, Hyman MC, Jung S, Littman DR, Weber C, Ley $\mathrm{K}$ : Circulating activated platelets exacerbate atherosclerosis in mice deficient in apolipoprotein E. Nat Med 2003;9:61-67.

-2 Furman MI, Barnard MR, Krueger LA, Fox ML, Shilale EA, Lessard DM, Marchese P, Frelinger AL 3rd, Goldberg RJ, Michelson $\mathrm{AD}$ : Circulating monocyte-platelet aggregates are an early marker of acute myocardial infarction. J Am Coll Cardiol 2001;38: 1002-1006.

\footnotetext{
3 Lutgens E, Gorelik L, Daemen MJ, de Muinck ED, Grewal IS, Koteliansky VE, Flavell RA: Requirement for CD154 in the progression of atherosclerosis. Nat Med 1999;5:1313-1316.

4 Mach F, Schonbeck U, Sukhova GK, Atkinson E, Libby P: Reduction of atherosclerosis in mice by inhibition of CD40 signalling. Nature 1998;394:200-203.

5 Henn V, Slupsky JR, Grafe M, Anagnostopoulos I, Forster R, Muller-Berghaus G, Kroczek RA: CD40 ligand on activated platelets triggers an inflammatory reaction of endothelial cells. Nature 1998;391:591-594.
}

\footnotetext{
6 Henn V, Steinbach S, Buchner K, Presek P, Kroczek RA: The inflammatory action of CD40 ligand (CD154) expressed on activated human platelets is temporally limited by coexpressed CD40. Blood 2001;98:1047-1054.

7 Lee Y, Lee WH, Lee SC, Ahn KJ, Choi YH, Park SW, Seo JD, Park JE: CD40L activation in circulating platelets in patients with acute coronary syndrome. Cardiology 1999;92:1116.
} 
8 Mach F, Schonbeck U, Bonnefoy JY, Pober JS, Libby P: Activation of monocyte/macrophage functions related to acute atheroma complication by ligation of CD40: induction of collagenase, stromelysin, and tissue factor. Circulation 1997;96:396-399.

-9 Urbich C, Mallat Z, Tedgui A, Clauss M, Zeiher AM, Dimmeler S: Upregulation of TRAF-3 by shear stress blocks CD40-mediated endothelial activation. J Clin Invest 2001;108:1451-1458.

- 10 Heeschen C, Dimmeler S, Hamm CW, van den Brand MJ, Boersma E, Zeiher AM, Simoons ML: Soluble CD40 ligand in acute coronary syndromes. N Engl J Med 2003; 348:1104-1111.

-11 Aukrust P, Muller F, Ueland T, Berget T, Aaser E, Brunsvig A, Solum NO, Forfang K, Froland SS, Gullestad L: Enhanced levels of soluble and membrane-bound CD40 ligand in patients with unstable angina. Possible reflection of $\mathrm{T}$ lymphocyte and platelet involvement in the pathogenesis of acute coronary syndromes. Circulation 1999;100: 614-620.
12 Varo N, de Lemos JA, Libby P, Morrow DA, Murphy SA, Nuzzo R, Gibson CM, Cannon CP, Braunwald E, Schonbeck U: Soluble CD40L: risk prediction after acute coronary syndromes. Circulation 2003; 108:10491052.

13 Schonbeck U, Varo N, Libby P, Buring J, Ridker PM: Soluble CD40L and cardiovascular risk in women. Circulation 2001;104:22662268.

14 Myocardial infarction and mortality in the coronary artery surgery study (CASS) randomized trial. N Engl J Med 1984;310:750758.

15 Clarke JL, Anderson JL, Carlquist JF, Roberts RF, Horne BD, Bair TL, Kolek MJ, Mower CP, Crane AM, Roberts WL, Muhlestein JB: Comparison of differing C-reactive protein assay methods and their impact on cardiovascular risk assessment. Am J Cardiol 2005;95:155-158.

16 Tanne D, Haim M, Goldbourt U, Boyko V, Reshef T, Adler Y, Benderly M, Mekori YA Behar S: CD40 ligand and risk of ischemic stroke or coronary events in patients with chronic coronary heart disease. Int J Cardiol 2006;107:322-326.

-17 Fitzgerald DJ, Roy L, Catella F, FitzGerald GA: Platelet activation in unstable coronary disease. N Engl J Med 1986;315:983-989.
18 Topol EJ, Serruys PW: Frontiers in interventional cardiology. Circulation 1998;98:18021820.

19 Michelson AD, Barnard MR, Krueger LA, Valeri CR, Furman MI: Circulating monocyte-platelet aggregates are a more sensitive marker of in vivo platelet activation than platelet surface P-selectin: studies in baboons, human coronary intervention, and human acute myocardial infarction. Circulation 2001;104:1533-1537.

20 Sarma J, Laan CA, Alam S, Jha A, Fox KA, Dransfield I: Increased platelet binding to circulating monocytes in acute coronary syndromes. Circulation 2002;105:21662171.

21 Ott I, Neumann FJ, Gawaz M, Schmitt M, Schomig A: Increased neutrophil-platelet adhesion in patients with unstable angina. Circulation 1996;94:1239-1246.

-22 Cipollone F, Ferri C, Desideri G, Paloscia L, Materazzo G, Mascellanti M, Fazia M, Iezzi A, Cuccurullo C, Pini B, Bucci M, Santucci A, Cuccurullo F, Mezzetti A: Preprocedural level of soluble CD40L is predictive of enhanced inflammatory response and restenosis after coronary angioplasty. Circulation 2003;108:2776-2782. 